\title{
Atame: performar o corpo maquínico despedaçado
}

\section{Atame: performing the dismantled mechanical body}

\section{Otávio Guimarães Tavares ${ }^{\mathrm{a}}$}

a Universidade Federal do Pará, Belém, Pará, Brasil - nonada1@gmail.com

Palavras-chave: Wilton Azevedo. Atame. Performance. Ação.

\section{Keywords:}

Wilton Azevedo. Atame. Performance. Action.
Resumo: Este ensaio explora a obra Atame: a angústia do precário do artista digital Wilton Azevedo tendo em vista a multiplicidade de versões disponíveis da obra - como performance ao vivo, versão interativa em DVD e vídeo-poema - e as possíveis implicações destes diferentes modos de operar. Ao mesmo tempo, lê-se a obra como marcada pela fragmentação corpórea em um cenário pós-rompimento amoroso, em que o corpo dilacerado da personagem se torna materialmente presente a partir do modo de navegar pela obra. Opera-se então uma dupla articulação em que a multiplicidade das diferentes versões da obra e a tentativa de reconstituição de um corpo perdido da personagem se apresentam como invariavelmente frustradas diante de uma tensão entre os elementos humanos e maquínicos que amarram o modo de ser atual da personagem e da obra.

Abstract: This essay explores Brazilian digital author Wilton Azevedo's work Atame: a angústia do precário in view of its multiple versions - as live performance, interactive DVD, and video-poem - and the possible implications of these different modes of operating. At the same time, I attempt to read the work as marked by the character's bodily fragmentation in a post breakup scenario, in which her dilacerated body becomes materially present to us by means of how we navigate through the work. What we have is thus a double articulation in which the multiple versions of the work and the character's attempt to reconstitute a lost body are presented as invariably frustrated by a tension between human and machine which ties the character's and the work's final mode of being. 
A piada é talvez a mais complexa das artes, arte esta que talvez seja a mais perfeita do artista e professor Wilton Azevedo, ou a que ele levou como base de todas as outras. Explico-me. A despeito da fama da piada como coisa simples, coisa tosca, coisa qualquer, é nela que exercitamos a perfeição da performance. É nela que precisamos o detalhe do ser outro, do ser fictício, do ser um artifício que, se não adaptado constantemente ao mudar das nuanças situacionais, falhará miseravelmente (e não há nada mais horrível do que uma piada mal contada ou fora do lugar). Este é um dos motivos que tornam a comédia e a sátira gêneros tão difíceis de traduzir para outras épocas e outros contextos. Ora, com Wilton Azevedo não havia jamais piada mal contada ou fora do lugar. Todas eram articuladas, todas eram uma perfeita encenação no palco do mundo. O exímio piadista sabia torcer e adequar tudo a toda situação, no mais exato improviso, no mais veloz das mudanças e, acima de tudo, na argúcia para uma piada respondida ou retrucada em que era capaz de montar piada em cima de piada, até que a plateia implorasse por um pouco de ar.

Não havia momento sem piada, não havia momento que não pudesse ser o inverso de si mesmo. O ponto máximo disto para mim foi quando, ao andarmos pela Universidade Federal de Santa Catarina, por ocasião do II Simpósio Internacional e VI Simpósio Nacional de Literatura e Informática organizado por Alckmar Santos e o NuPILL em 2013, este que escreve quase o deixou cair com seu carrinho motorizado para dentro de uma vala achando que se tratava de uma piada genial, i.e., fingir que se estava caindo em uma vala. Foi só no último momento que Wilton quebrou o encanto piadístico com um "não é piada, eu vou cair, ele [o carrinho] não segura nesta inclinação". No fim das contas, a piada era constante.

Talvez seja o caso de pensar piadas, aqui, como modo de vida, como modo de subverter o mundo, subverter a loucura suprema desta realidade. Não é atoa que Samuel Beckett, talvez o maior dramaturgo do século XX, em suas peças, fazia coabitar o horror e o humor quase chapliniano. E Rosencrantz e Guildenstern, na peça homônima de Tom Stoppard (1991), mesmo quando suas vidas pendem constantemente na balança do acaso, estão sempre às voltas com piadas. Isso talvez, porque há algo muito sério sobre se contar piadas. A cada piada, invertemos a realidade e reescrevemos o mundo, talvez para melhor.

No caso de Wilton, envolto em computadores e máquinas, até mesmo para ação mais básica de se locomover, a piada pode caracterizar um traço humano que vai muito além da dificuldade contextual e semântica que ela impõe a sistemas maquínicos (que tendem, ainda, a 
ter problemas em replicar a ginga pragmática da linguagem). Contar piadas é então, talvez, um ato primordialmente humano e que mostra nossa resistência nesse mundo tecnificado e produtivista, da mesma forma que produzir arte digital também seja.

Acredito que esse belo modo de ser de Wilton Azevedo tenha implicações em sua obra artística. Ser um piadista exemplar é também ser um performer exemplar. É saber as regras do grande teatro do mundo e subvertê-las a todo instante. Acredito que este seja um dos eixos centrais para compreender a obra artística de Wilton Azevedo.

\section{II}

O âmbito do fazer de Wilton se encontra num limiar histórico; um artista criado em um mundo analógico na entrada do digital, e que habitou esse último espaço com toda ambiguidade necessária. Aqui, gostaria de olhar uma obra específica dentre a constelação que o cerca. Esta é a obra Atame: a angústia do precário (2006). Entretanto, ao dizer "obra específica" já crio um problema complexo ou, no mínimo, uma relação ambígua. Isto se deve ao fato de que a obra em questão, como o ser de Aristóteles no livro Gama de sua Metafísica, se diz de várias maneiras. Atame foi performance, é DVD e é, mais acessivelmente, um vídeo disponível no Youtube. Qualquer pessoa que diga que experienciou a obra Atame teria que, a princípio, dizer com qual destas se relacionou, com qual obra entrou em contato, qual tocou, tendo em vista que as relações do modo de operar de cada versão implicam em experiências bastante diversas. Ademais, também não há como nivelar as versões em qualquer tipo de "escala" ou "hierarquia" em que uma seria mais "verdadeira" ou mais "original" que as outras. A ordem de produção nada nos auxilia, e recorrer a tal fato seria um modo meramente conveniente de criar uma ordem cômoda que pouco diria sobre os modos de operar. Estamos relegados ao inexorável prazer da multiplicidade, restando ao usuário, no mínimo, três possibilidades de contato diferentes, tendo vista que, dentre tantas coisas: 1) a performance é efêmera e alterada no momento de seu acontecimento sobre os improvisos do próprio autor, como se dava nas performances musicais de Wilton como Duo Pantharei ${ }^{1}$; 2) o DVD é uma obra interativa em que o usuário deve escolher seus possíveis caminhos a trilhar através de seu toque digital, estando calcado ao loop e reiterações constantes, em grande parte derivados de suas próprias escolhas ou percalços de caminho; e 3) o vídeo no Youtube é um monólogo de uma personagem sem corpo que se arrasta e se multiplica em sombras pela tela, carregando

\footnotetext{
${ }^{1} \mathrm{E}$, tristemente, nunca mais a teremos.
} 
os ares de um longo vídeo-poema ao mesmo tempo que encena laços com a vídeo-arte e o cinema de vanguarda, e tem a enorme vantagem de estar plenamente disponível online.

Trata-se, obviamente, apenas de um esboço, pois a complexidade das diferenças é ainda muito mais vasta em suas implicações, tanto no que concerne ao modo de ser da obra, quando à recepção por parte do usuário. Experienciar uma destas obras não implica em ter experienciado as outras. Estamos, como talvez Wilton tivesse se divertido em ver, perdidos entre a piada e a piada; três opções, todas encenações de si mesmas, todas “originais".

Um caso interessante que pode nos auxiliar na compreensão de Atame seria o caso de Der Schrei der Natur de Edvard Munch. O que é normalmente pensado como sendo um quadro é na verdade uma pluralidade, i.e., são quatro versões de diferentes materiais (óleo, pastel, têmpora) e uma pedra de litografia (que, invariavelmente, permitiria diversas cópias). Todas são obras de Edvard Munch, todas são, tecnicamente, Der Schrei der Natur, mas todas são obras diferentes. Trata-se da mesma composição, mas de diferentes pinturas. Caso um pouco próximo de diversas pinturas antigas que contam com mais de uma versão, sendo várias versões pintadas por copiadores ou discípulos, prática bastante comum, e mesmo encorajada, durante o renascimento. É o caso, possivelmente, da Paisagem com a Queda de Ícaro, longamente atribuída a Pieter Bruegel, exposta no Museu dos Velhos Mestres dos Museus Reais de Belas-Artes da Bélgica em Bruxelas. São situações em que as tentativas de precisar um original ou versão primeira desandam e revelam um emaranhado de encenações. Mais do que a obsessão pela gênese, que irá sempre dar em um beco falacioso, vale a compreensão diante da multiplicidade. Wilton nos deixou uma piada em que todos os Atames - aqui no plural - são originais e cópias, são ensaios de si mesmos.

No fundo, poderíamos indicar que o usuário "teria" que escolher um Atame para trilhar e seguir a falar sobre este. Ou teria? Talvez aqui possamos incorrer em um erro ao tentar presumir que um usuário, hoje, teria que se deparar com apenas uma versão de Atame. Pareceme um pouco destoante à nossa época, e ao funcionamento do mundo digital contemporâneo, tentar nivelar o contato com a obra, criar para ela restrições quando nenhum lugar as implica. Talvez mais provável seja um contato disforme e precário - como indica o próprio subtítulo da obra - em que o usuário encontre mais de uma versão e, ainda, agregue a ela e seu contato outros elementos que circundam na internet como os poemas de Atame transcritos e os comentários e relatos do próprio autor (que os deixou em diversos artigos pela rede). Portanto, 
à multiplicidade dos modos de ser de Atame se somam outros ainda mais esparsos, formando um amálgama artístico digital em que Atame se faz de fragmentos de si mesma, faz-se desta precariedade das múltiplas versões que flutuam após a ida de seu autor. Talvez seja apenas confrontando esse amálgama não definitivo que poderemos fazer jus a essa obra verdadeiramente expandida.

\section{III}

Nesse jogo, poderíamos questionar até que ponto os comentários e a transcrição dos versos, por exemplo, poderiam ser considerados como parte da obra. Sobretudo porque não se encontram no "corpo da obra" de forma direta (os versos, por exemplo, mesmo estando na obra, são ouvidos e não lidos e isso ainda, no DVD, se dá de forma muito mais aleatória e sem uma aparente ordem de continuidade narrativa que pode ser inferida a partir da leitura dos poemas impressos ou na versão do Youtube). De um modo um pouco invertido, seria possível perguntar se as versões digitais não seriam encenações ou concretizações dos takes e poemas escritos, no sentido de que a obra de arte seria o texto e a performance apenas um elemento contingente extra. A questão é, portanto, de nos perguntarmos pelo limite de Atame e da recepção desta.

Talvez o ponto a ser notado seja que a ideia de autonomia da obra de arte é um conceito tardio na história das ideias artísticas, tendo entrado em questão nos séculos XVIII e XIX. É de certa forma esta noção que imprime a primazia de um original "único" ao mesmo tempo em que condena a ideia de uma "explicação", entendendo esta como um item externo ao corpo da obra ou um elemento não-estético que só interfere com a apreensão sensório-perceptiva da obra. Não obstante, se observarmos a produção letrada seiscentista encontraremos diversos exemplares, sobretudo no que tange a poesia-visual ou labirintos poéticos, que são um composto entre poema - propriamente dito -, explicações de uso e comentários entre outros engenhos $^{2}$. A arte conceitual contemporânea também renega a concepção estética ao considerar a obra não só como o produto físico final, mas também o conceito que a gerou e os procedimentos de produção. Fato bastante claro no Three and One Chairs de Joseph Kosuth em que a obra não é o resultado final de cadeira-foto-definição, i.e., o resultado retinal - para

\footnotetext{
${ }^{2}$ Veja os exemplos apresentados por Ana Hatherly em seus livros A Experiência do prodígio: bases teóricas e antologia de textos-visuais portugueses dos séculos XVII e XVII (1993) e A Casa das musas (1995) e os apresentados por Rafael de Cózar em seu Poesia e imagem: formas difíciles de ingenio literário (1991).
} 
usar a noção de Duchamp $(1990)^{3}$ - mas sim a instrução para construção deste conjunto variável de perceptos ${ }^{4}$. É interessante notar que a ideia da obra performática como mero desdobramento do texto, a que deveria fidelidade, é também uma concepção gestada nos séculos XVIII e XIX, como mostra Theresia Birkenhauer (2012). Se olharmos de volta ao teatro elisabetano, por exemplo, veremos que a lógica do texto teatral era de um texto para performance, e não para leitura silenciosa autônoma. Este era passível de diversas alterações de performance em performance ${ }^{5}$. Contemporaneamente, podemos pensar na proposta de Hans-Thies Lehmann (2006) de um teatro pós-dramático em que não há uma noção de hierarquia entre texto e performance, muito menos uma restrição de que seja apenas o texto teatral que possa ser performado. O que está em jogo aqui não é, portanto, uma mera aceitação de um "extra" à obra (se este importa ou não para apreensão da obra) ou noções de fidelidade, mas sim o modo de ser da obra de arte. Estas questões implicam a recepção, mas têm sua origem em uma ontologia da obra de arte, compreendendo ontologia ao modo proposto por Celso Braida (2013) como um estudo e análise de estruturas formais-conceituais das nossas práticas discursivas, estruturas implícitas nos nossos modos de agir, perceber, pensar e dizer o mundo (mesmo quando não nos demos conta destes). Portanto, os problemas da arte digital não podem ser abordados meramente como questões de fundamento epistemológico, mas antes como questões ontológicas que implicam nosso modo de perceber, pensar, dizer e agir.

\section{IV}

Dentro desta linha, Francisco Ricardo (2009), ao tentar esboçar a base da teoria da arte mídia - media art theory - levanta dois eixos que se distanciam e convergem nos estudos da arte e literatura digital. Estes seriam o foco sobre o mecanismo da obra digital ou sobre a experiência que a obra gera. Ricardo recorre à tese de que os meios tradicionais, como literatura e pintura, respectivamente com a página impressa e o cavalete, dependeriam de um meio relativamente estável e fixável. Seria a partir da força imaginativa do leitor ou espectador que a ação ocorreria. Haveria, portanto, nos estudos das artes, certa tendência em focar na leitura ou na recepção. Entretanto, o meio móvel da arte e literatura digital, com sistemas de interação, gerações aleatórias e caminhos possíveis, impossibilitaria o foco único na recepção. Obviamente, as artes não-digitais já contavam com esse tipo de produção. Ela se

\footnotetext{
${ }^{3}$ É Duchamp justamente quem argumenta justamente que devemos recusar o estritamente retinal e o estético.

${ }^{4}$ Discuti esse problema de maneira bastante detalhada em minha tese Ação e artifício (2015).

${ }^{5}$ É a tese sustentada por diversos pesquisadores de que o Hamlet do primeiro in-quarto de 1603 seria uma versão para encenação (talvez em situações mais rápidas e com menos atores disponíveis) (O’SHEA, 2013).
} 
encontra nas artes conceituais, nos livros-objetos, nos procedimentos performáticos, na literatura oral e tantas outras produções. A questão a ser notada é que a arte digital torna essa instabilidade, essa precariedade, o modo padrão de seu meio, inclusive brincando e dissimulando a si mesma com graus diferentes de apresentação de seu modo de operar. Isso porque nem sempre a complexidade de um algoritmo é espelhada na face entregue ao usuário - no objeto que ele percebe - da mesma forma que uma obra visualmente interessantíssima não necessariamente implica uma programação complexa ou extensa. Estes movimentos e tensões fazem parte da produção digital. O que fica vigente é, até certo grau, a necessidade de abordar essa dualidade entre mecanismo e experiência de forma aberta e rigorosa.

O caso de Atame se torna, portanto, ainda mais esquivo. As múltiplas versões da obra devem ser reconhecidas como distintas em seus modos de operar, cada uma com suas particularidades e implicações em termos de mecanismo e experiência. Mas é possível ainda, como sugeri acima, pensar o modo de navegar os Atames como faces de um mesmo conjunto, desde que não impliquemos nesse modo de interagir uma totalidade intencional, como se todas as versões do Atame fossem parte de um Atame único e superior, pois este modo de pensar nos lançaria à projeção de uma transcendência inexistente. É, portanto, necessário ter claro que olhar qualquer versão de Atame é olhar uma multiplicidade heterogênea singular. Posso colocar cada versão diante da outra, posso usar uma para pensar a outra, posso intercalar leituras, e isso só será possível se reconhecer cada Atame como entidade própria e heterogênea.

Tendo abordado este problema, passemos ao desenrolar de Atame.

Atame constrói, em um cenário pós-rompimento amoroso, um discurso da fragmentação do corpo que invariavelmente, também deve ser entendido como a fragmentação de um "eu" diante da relação amorosa e da memória. Esta dupla fragmentação se encontra completamente atravessada por elementos tecnológicos. 
Fig. 1 - Tela inicial da versão em DVD.

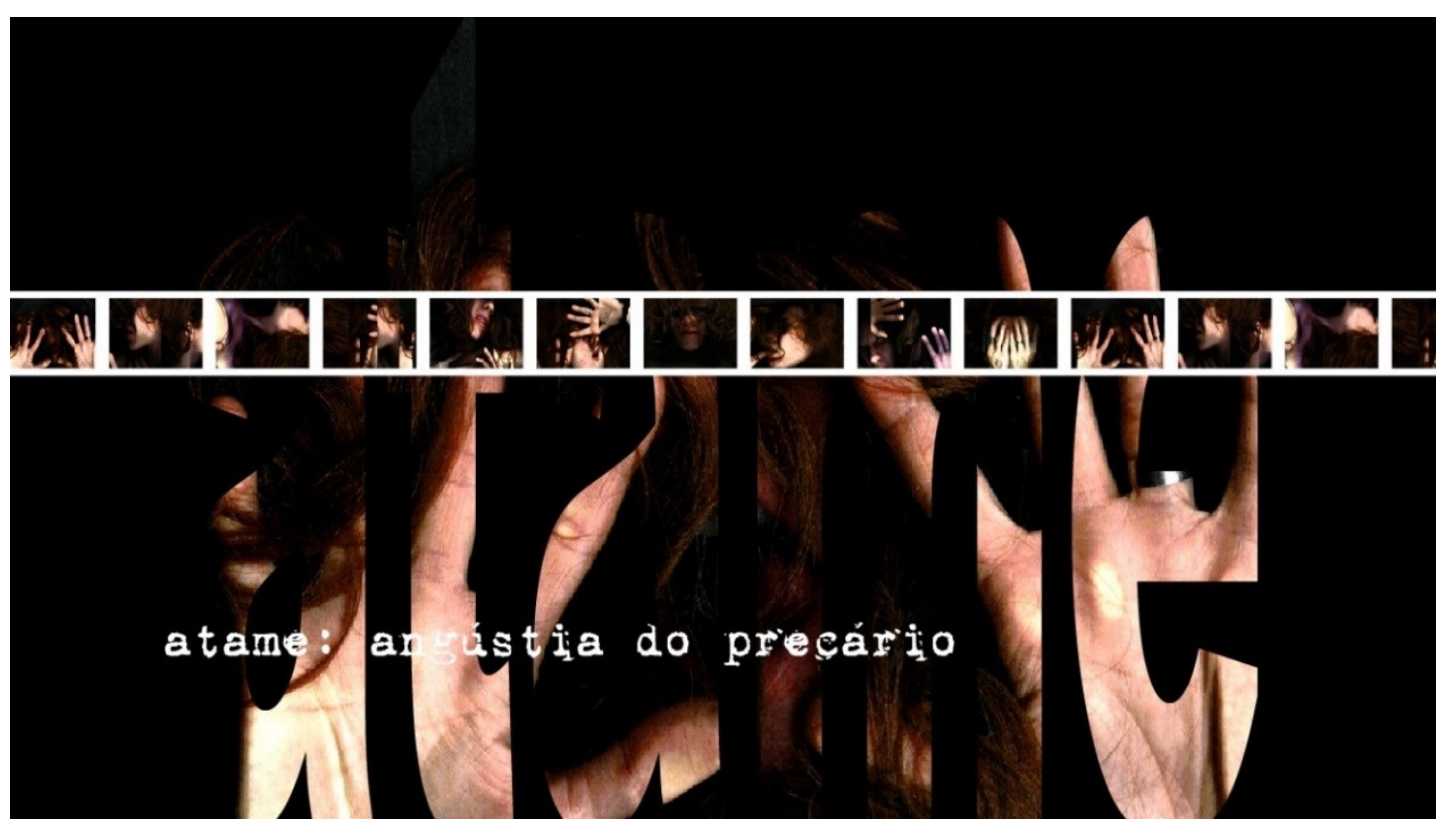

Concretamente, na versão em DVD - talvez a versão mais inusitada por seu caráter materialmente interativo -, temos onze instâncias ou telas com múltiplas sub-telas, todas compostas por voz (que vocalizam os takes e poemas), imagens/vídeos de pedaços do corpo da atriz, sons, música, interatividade e textos. Para quem tentou ler os takes e poemas antes, a situação em tela se apresenta como bastante diversa. Tenho dúvidas de que os curtos poemas foram feitos para serem ouvidos por completo. A lógica da navegação online tende a não comportar bem longos tempos de espera, sobretudo quando cada detalhe chama o usuário a clicar, mover, arrastar e continuar seu percurso por esse corpo/eu dilacerado. Provavelmente foi com este fato em mente que Wilton construiu as telas como pequenos pedaços, breves movimentos que pedem rápidos gestos para que as telas sigam e possamos continuar a navegar, mesmo que isso implique em cortar, interromper, sair ou forçar adiante algo que ainda acontece. 
Fig. 2 - Uma das telas do Atame em DVD.

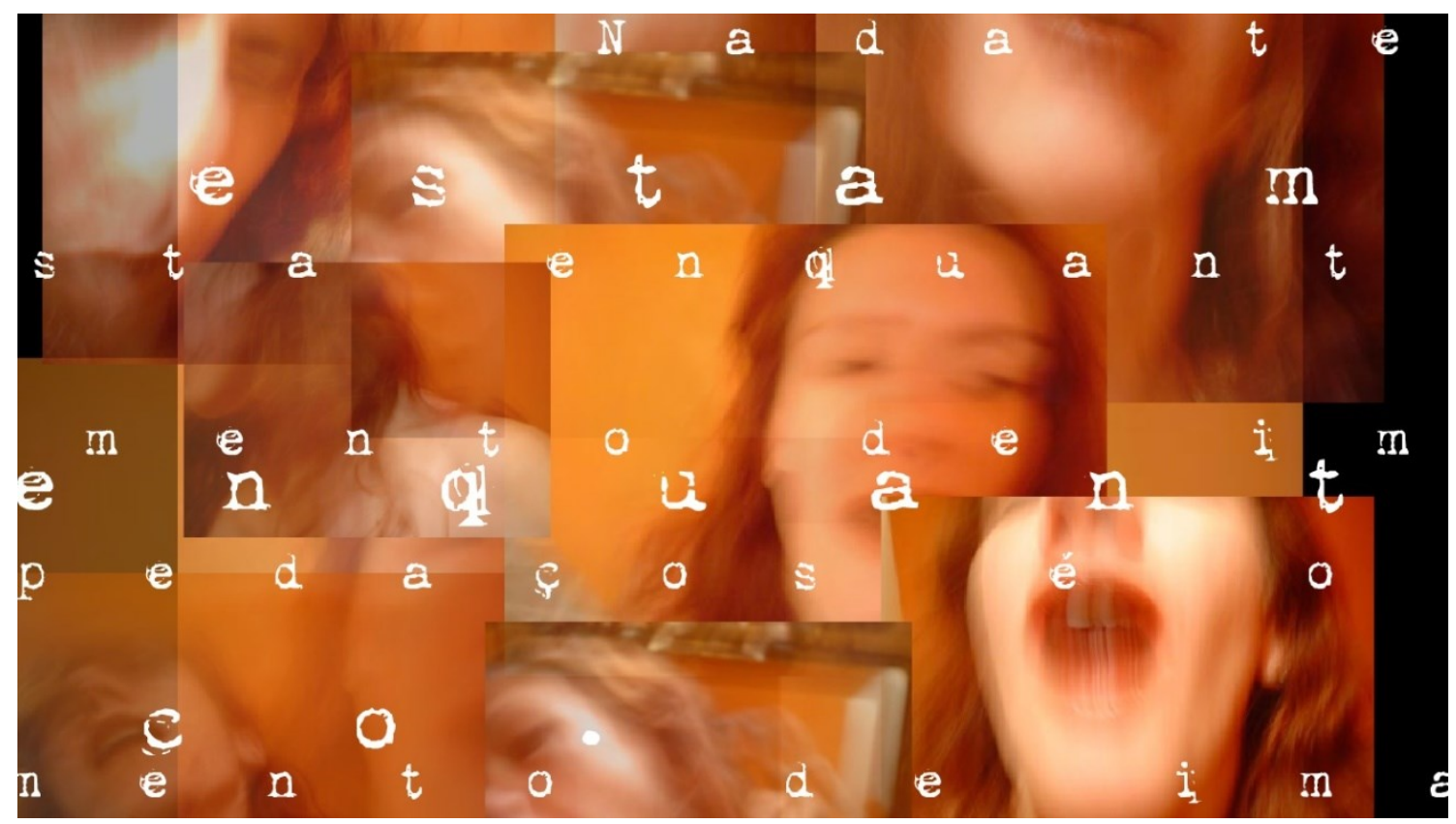

Talvez o elemento mais interessante do poema seja a presença do corpo e o fato que as telas constantemente trazem imagens ou fotos de pedaços da atriz em movimento. Isso porque, dentro da temática amorosa e das noções de perda, ausência e memória, o poema não só fala sobre o dilaceramento precário do corpo, mas o encena. Ele não se limita a contar sobre o rompimento, mas tenta efetivá-lo diante nós em sua complexidade. Ele mimetiza essa fragmentação através da pluralidade de telas-poemas, imagens de pedaços do corpo da mulher e da possibilidade não linear da leitura em que vemos o corpo em seus mil ângulos, mas não o temos como totalidade. Fato, por si, que serve também como metáfora para as múltiplas versões do Atame. 
Fig. 3 - Exemplo de tela com texto, som, e imagens do Atame em DVD.

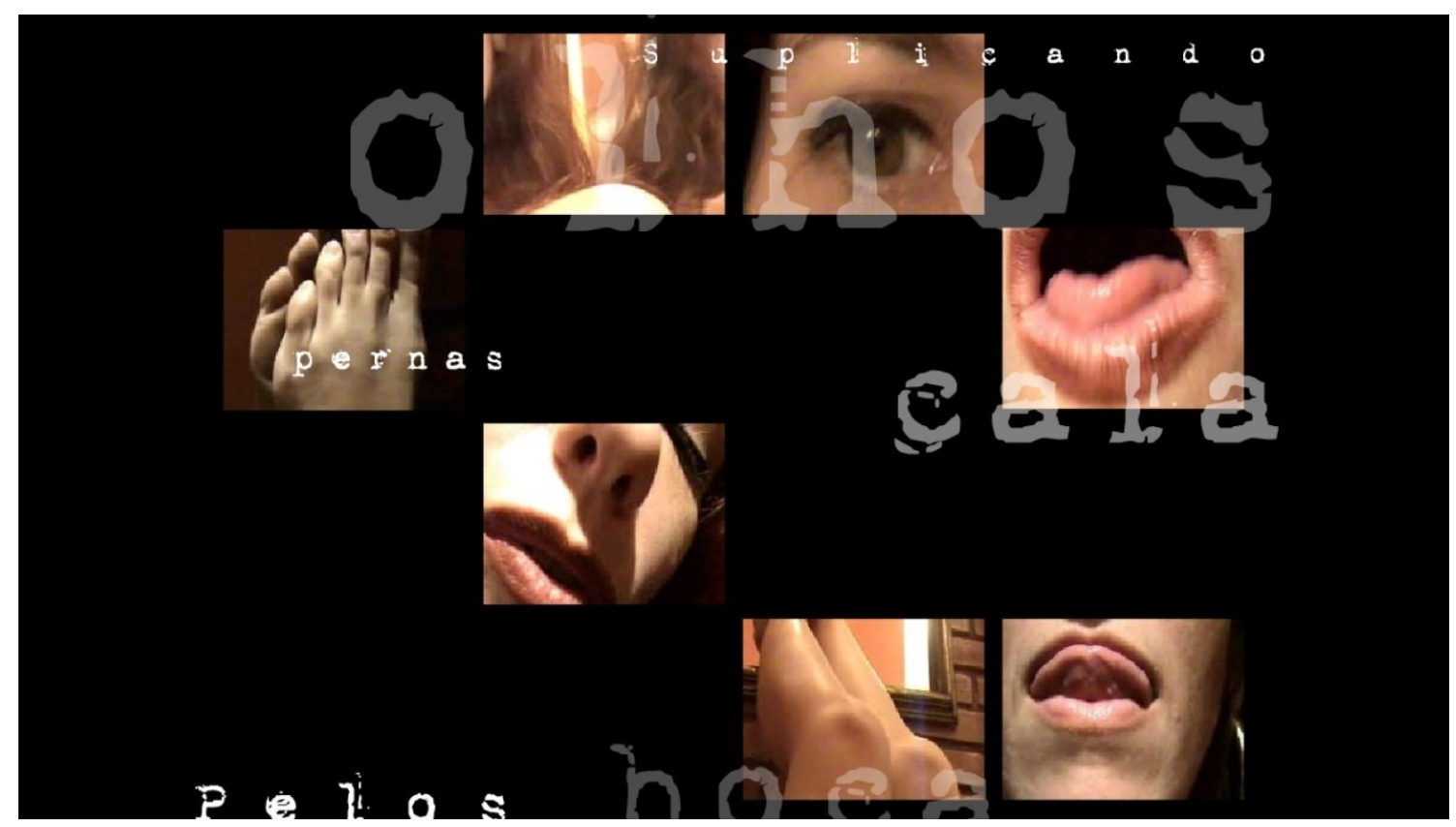

Se pensarmos o modo de navegação, este sutilmente leva em consideração a lógica digital e a usa para si, mas mais do que isso, ele evidencia a noção de um corpo - uma totalidade - que não para de ser recortado, quebrado e desfeito por gestos cotidianos da navegação digital. A obra, portanto, cria um paralelo entre nossos hábitos de navegação online - que, como hábitos, operam a despeito de uma consciência objetivante - e os nossos comportamentos amorosos, nossos vícios, egoísmos, traumas, fetiches e gestos que constantemente se manifestam diante do entrelaçar amoroso com um outro, tornando o mover-se pela obra em um mover e dilacerar um outro, mover pelo outro dilacerado.

Fig. 4 - Exemplo de tela do Atame em DVD.

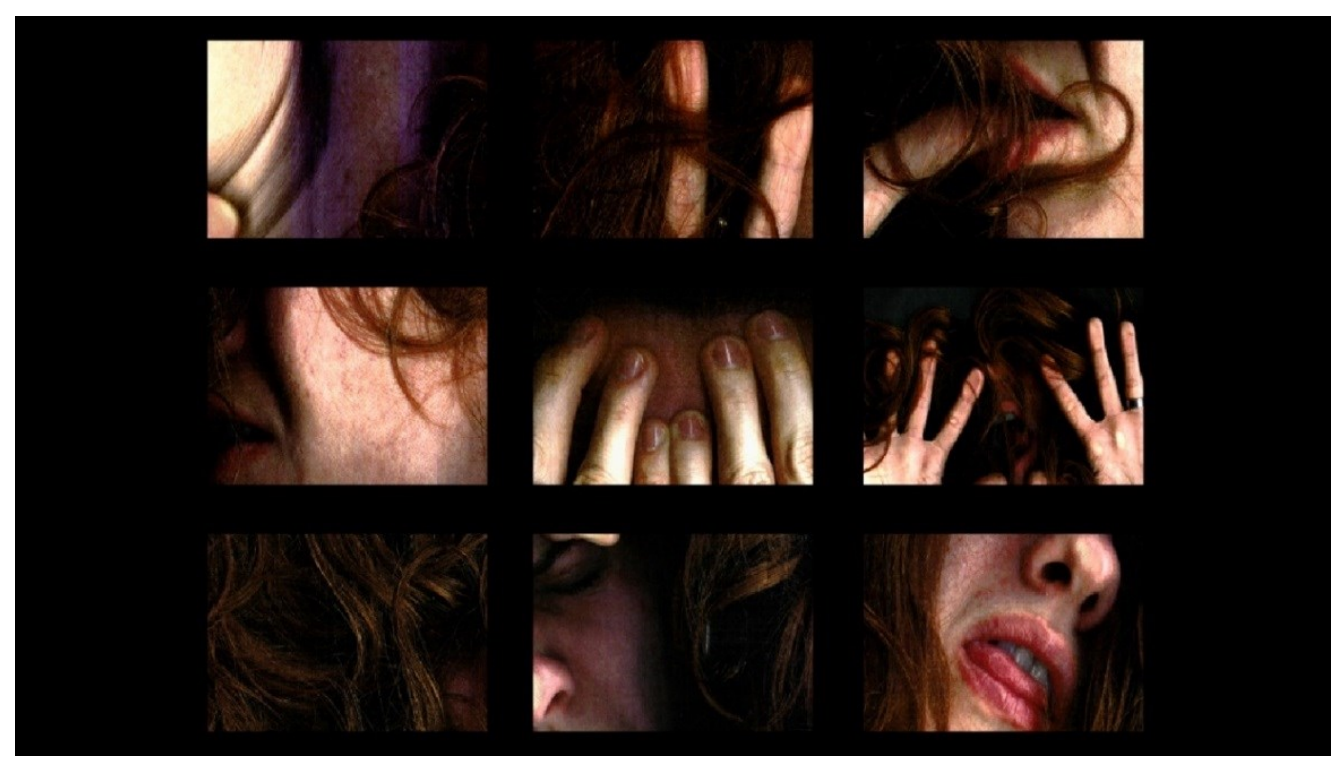


As telas do corpo que aparecem na obra seriam o fruto da personagem que escaneia partes de si mesma de modo que estas passam a operar como fotos. Estas carregam ainda uma espécie de projeção do toque, do corpo em potencial contato com o amante, são uma espécie de resquício e, ao mesmo tempo, substitutos do tato, do liso e rugoso corpóreo, uma emulação do toque do outro ou uma oferta e abertura ao toque pela máquina. Estas fotos podem, ambiguamente, serem vistas como fragmentos de um todo, ou as partes efetivas individuais. São pedaços de um mesmo quebra cabeça, mas que não se encaixam precisamente. Elas se sobrepõem, se entrelaçam, indicam uma mesmice, uma região de contornos e formas, um laço de união, mas que jamais, pela diversidade de ângulos e poses, podem ser restauradas a uma unidade. Temos a impressão da possibilidade da união, talvez indicada pela consonância e consciência de nossos próprios corpos que se indicam e se comparam, mas que jamais se recompõe. Mesmo assim, há vestígios, no Take 28, de uma tentativa da construir um corpo talvez outro - na performance quando a voz da personagem diz:

\author{
Redesenhando todo o meu corpo \\ Em cada parte que você tocou \\ Eu agora faço o mesmo \\ Apenas apertando um botão (AZEVEDO, 2006, TAKE 28)
}

O ato obviamente não sucede. Ao longo do poema, esta tentativa de reunião é confrontada constantemente à memória do amante, ainda marcada no corpo e como a voz da mensagem da secretária eletrônica; não uma mensagem deixada, mas a mensagem que pede para que se deixe uma mensagem após o "beep". Esta voz gravada do amante confunde-se, assim, com o espaço de vivência da própria narradora, com a voz que deveria ser desta. A secretária, então, contém os laços de memória pela voz do amante:

É estranho saber que o único botão que tenho para apertar, pode contar a história de uma paixão. (AZEVEDO, 2006, TAKE 1)

A máquina se torna, portanto, também o espaço da memória em que a paixão pode ser revivida a partir dos contatos e mensagens mínimas. Os laços sensórios - cheiro, toque, voz -, marcas de um corpo, são justapostos à ausência de corpo do amante que subsiste como presença através da máquina, como memória não-humana, parte estranha dentre o emaranhado do corpo feminino. Ao mesmo tempo, a personagem se lança a outro contato com a máquina ao escanear partes do corpo, criando um emaranhado de fotos, fragmentos moventes desunidos de si. Pode-se supor, talvez, que o duplo ato da performance maquínica - 
voz na máquina e imagens do corpo escaneado que se mexem e falam - seja uma forma de se reunir novamente, retornar à paixão, e tornar algo do amante seu:

\author{
Apenas tenho percebido, que meu corpo desde o fio de \\ cabelo até a ponta dos meus pés, \\ Passam a impressão de que sou feita de pedaços \\ Registros de pedaços. \\ Acredito que \\ As pessoas se amam em pedaços, \\ Se tudo acontecesse por inteiro \\ Não haveria paixão, \\ Somente amor (AZEVEDO, 2006, TAKE 2)
}

Os pedaços metafóricos são, no poema, pedaços efetivos. A voz na máquina e o corpo feminino dilacerado que fala e se movimenta a despeito de si, lembram o Krapp de Krapp's Last Tape e a boca verborrágica no palco de Not I. As duas peças de Samuel Beckett (2011) são marcadas por uma ideia parecida de um corpo dilacerado ao dissociar agir e dizer em falas sem corpos, corpos sem fala e o descompasso entre o que se vê e o que se escuta. A obra de Wilton frequenta esse mesmo espaço, entretanto não ocupado pelo desconcertante horror beckettiano, mas por uma sensualidade de formas, sentidos, cores e vozes, em que somos deixados apenas com pedaços, que recolhemos e reorganizamos, mas que jamais retornam ao seu estado de origem, perdida para sempre.

\title{
VI
}

Esse movimento se torna também visível, mesmo de outra forma, na versão disponível no Youtube ao construir um longo vídeo-monólogo em que sombras da narradora erigem sua história, de forma aparentemente mais linear, a partir de um canto de um apartamento. Esta versão em filme tem ares de uma câmera de vigilância constantemente ligada, fixa no mesmo local, com imagens turvas, pouco discerníveis e em que diferentes sobreposições de imagens temporais da personagem - como uma série de sombras de si que vão sendo continuamente sobrepostas em seus afazeres da sala, ao lado da secretária eletrônica - nublam a noção de presente, como se diferentes momentos tivessem sido sobrepostos ao modo do Here de Richard McGuire (2014). 
Fig. 5 - Atame na versão em vídeo no Youtube.

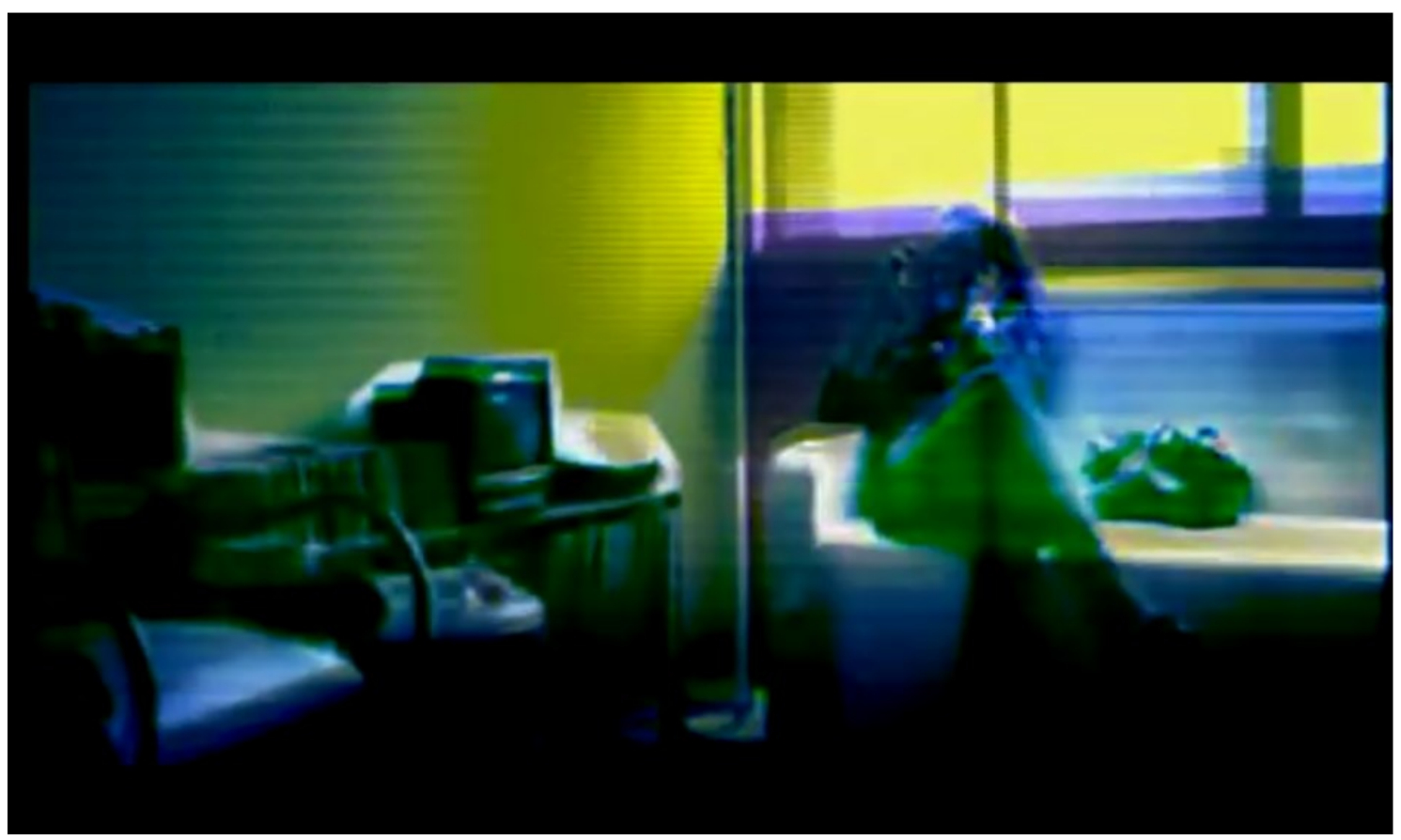

Diante da temática pós-rompimento, esta versão pode adquirir tons de imagens capturadas por uma câmera de vigilância deixada pelo amante, uma câmera oculta, em que nós, nós que assistimos, somos submetidos a esse ponto de vista único - reparemos aqui que a performance e a versão digital não nos submetem a essa fixidez do olhar -, somos colocados no papel de um espia erótico do corpo alheio e que permanecerá sempre estranho, por mais que passamos a conhecer a personagem diante de seu perambulante devaneio.

Diante desta hipótese interpretativa, o jogo da estranheza do corpo é feito por outro modo do que na versão interativa. Se na versão em DVD o corpo era estranho por sua fragmentação material explícita, no vídeo, ele se torna estranho por um contato fixo e direto constante, quase em forma de uma prisão do nosso olhar que cria uma dupla submissão: do corpo que é observado - com a privacidade violada - sem saber, e nós que não temos escolha diante do vídeo exceto assistir os movimentos deste corpo diante de uma câmera/olhar que nós não escolhemos. A visão ou câmera opera então como um ponto de intersecção entre duas prisões, nossa e do corpo da personagem.

Ao mesmo tempo, poderíamos inferir uma encenação no agir da personagem, como quem intui a câmera ou o olhar do outro e age de acordo com esse olhar presumido em um ato inverso de reconstruir o olhar do outro a partir dos movimentos esperados como se o outro a olhasse. Isso cria um entrelaçamento entre olhar presumido e efetivo, ação presumida e 
efetiva, um entrelaçamento ambíguo em que o outro pode ter parado de ocupar o lugar, mas ainda é criado ou projetado ali pela ação da personagem. Trata-se de um local em que um eu e um outro se encontram presos em uma dança de vazios, uma dupla insinuação amorosa. Há uma vigilância interiorizada que se mostra dupla insinuação e sedução, mas sedução da máquina, pela e para máquina que, ao lado do escâner e da voz da gravadora, cria o outro a partir da máquina.

Judith Butler, em seu livro Precarius Lives: the power of mourning and violence (2006), compreende o corpo humano como o local de uma vulnerabilidade, talvez nossa vulnerabilidade fundamental e absolutamente compartilhada. Esta vulnerabilidade é tanto fisiológica quanto social, tendo implicações intersubjetivas, perante o fato de ser uma característica inerente a todo ser humano. Neste sentido, a vulnerabilidade, implica também uma constituição política. Ao mesmo tempo, Butler afirma que a perda e a vulnerabilidade se dão por sermos corpos socialmente constituídos. Nossa ligação com outros abre ao perigo, sempre iminente, de perdermos estas ligações ou sofrermos violência em virtude desta exposição.

Se, como indica a autora, somos sempre lançados e constituídos por um outro, poderíamos propor que a perda do amante em Atame se esboça sobre o vazio a partir de uma reconstituição maquínica performativa. Isto é, a personagem intenta reestabelecer o vazio da perda pelo viés maquínico. Ao mesmo tempo, o aparato tecnológico serviria para dar conta de um eu fragmentado a partir da projeção do outro perdido.

Se a pergunta de Butler é: o que conta como vida? Ou, como se configura esse enquadramento do que é considerado vida, o drama pós-rompimento de Atame pode ser compreendido como um drama em que a perda do outro é também a perda de humanidade rumo a uma desumanização que encontra saída em uma estranha re-humanização maquínica, em que continuar vivendo, continuar sendo sem a presença do amante se dá por uma série de próteses.

Se prensarmos as noções de Butler (2006) ao lado das análises de Maurice Merleau-Ponty (2006), entenderemos que o corpo humano deve ser compreendido como um construto múltiplo, erguido por normas, instituições, discursos, ideias, afetos, contatos, e, ao mesmo tempo, por próteses e entrelaçamentos de outros artefatos tecnológicos inanimados que são 
trazidos a constituir o corpo fenomenal. Há um intercalar do corpo como construto entre elementos materiais e não-materiais (institucionais) na medida em que as próteses também implicam relações éticas com outrem e as normas e elementos sociais também podem ser compreendidas, como indica Amie Thomasson (1999), como artefatos abstratos. A divisória entre tecnológico e não-tecnológico se torna, portanto, cada vez mais tênue diante de uma sociedade hipertecnificada em que os aparatos progressivamente se desmaterializam e se incorporam ao nosso corpo.

O canto do quarto fixado pelo enquadramento da câmera, por exemplo, cria um confinamento sem amarras materiais. Gilles Deleuze em seu "Post-scriptum sur les sociétés de contrôle" (1990) notou que, no século XX, passamos de sociedades disciplinares para sociedades de controle, passamos de uma prisão de paredes para uma prisão imaterial. A vigilância pode ser vista então como criando uma prisão em que o impedimento, a restrição propriamente dita, não se dá pelas paredes, nem pela força física, mas pelo olhar do outro, ou, talvez, a vigência do olhar da personagem sobre o olhar maquínico que a observa. Vigilância, amor, controle, se deixar vigiar, ou autovigilância, são, talvez, entrelaçamentos doentiamente perfeitos de nossa sociedade. O ato de estar com o amante, de recuperar a perda, se torna o de trazer esse aparato tecnológico para si, se colocar constantemente com esse aparato.

O amante se faria presente não só pela voz da mensagem de recepção da secretária eletrônica e pelo toque do corpo fotocopiado pelo escâner, mas também por um modo de olhar, ou uma escolha do ponto de visão. Ele se tornaria virtualmente presente pela voz, visão e toque. Voz dele gravada, visão fixada para outrem, toque dele no corpo escaneado. Tudo isso permitiria a ele uma espécie de presença 24/7 - para lembrar Jonathan Crary (2014) - em que os meios digitais não permitiriam então a personagem uma fuga do amante, pois ele se faz constante para além das possibilidades físicas. Ele se faz mídia em uma sociedade capitalista 24/7, como uma autovigilância perfeita.

A separação efetiva se torna uma tarefa infindável e impossível, uma luta contra o estar desperto, contra um modo de vida em uma sociedade digital do capitalismo tardio, mas também, estranhamente, é a relação com a máquina que suplanta essa perda e vulnerabilidade da perda, e ela que permite a continuidade. 
Termino, portanto, notando que a multiplicidade da obra em seus vários modos de ser pode também ser conjugado com a multiplicidade do corpo despedaçado da personagem e a multiplicidade do amante como emulação através de aparatos tecnológicos. Todas estas indicam um caminho sem volta, indicam que não há como restaurar nem um nem outro. A tentativa de reconstrução efetivada pela personagem evidencia um mundo em que ser passa a ser tecnológico ao mesmo tempo em que ser humano - vulnerável - é também ser afetável pelos artefatos maquínicos, mesmo que haja uma estranha ambiguidade nestes contatos.

Começo pela piada e termino com a relação da personagem tentando se reconstruir em um limiar de humano, tendo em vista um problema material ético. A ligação é tênue, mas existe. Se no começo mencionei a predominância da piada como indicação do humano, agora marco que o modo de operar da piada talvez seja a indicação da relação em vigor em Atame, i.e., de um torcer e subverter a realidade. Em Atame a personagem se entranha no maquínico, mas, ao mesmo tempo, o subverte, o torna seu, o torna táctil, sonoro, visível, o torna corpóreo e humano.

Por fim, Atame nos enrola, nos coloca problemas que não enredam soluções fáceis, nos lançando sobre dúvidas e desvios que nos colocam a virar sobre nós mesmos. Atame, como a arte da piada, coloca o mundo às avessas e desmantela nossas certezas sobre a arte e o que é ser humano. Nesse sentido, o fazer do Wilton é sempre este, humano.

\section{REFERÊNCIAS}

BECKETT, Samuel. Selected works of Samuel Beckett. New York: Grove Press, 2011.

BIRKENHAUER, Theresia. Entre fala e língua, drama e texto: reflexões acerca de uma discussão contemporânea (trad. Stephan Baumgärtel). Urdimento: revista de estudos em artes cênicas, Florianópolis, n. 18, p. 181-188, mar. 2012. Disponível em: $<$ http://www.revistas.udesc.br/index.php/urdimento/article/view/3235/2356>. Acessado em: $01 / 04 / 2018$.

BRAIDA, Celso R. Tópicos em ontologia. Florianópolis: Rocca Brayde, 2013. 
BUTLER, Judith. Precarius lives: the power of mourning and violence. New York: Verso, 2006.

CÓZAR, Rafael de. Poesia e imagem: formas difíciles de ingenio literário. Sevilla: El Carro de la Nieve, 1991.

CRARY, Jonathan. 24/7: Late Capitalism and the Ends of Sleep. New York: Verso, 2014.

DELEUZE, Gilles. Pourparlers 1972-1990. Paris: Les Édition Minuit, 1990.

DUCHAMP, Marcel. Engenheiro do tempo perdido: entrevistas com Pierre Cabanne. (trad. António Rodrigues). Lisboa: Assírio \& Alvim, 1990.

HATHERLY, Ana. A Casa das musas. Lisboa: Estampa, 1995.

. A Experiência do prodígio: bases teóricas e antologia de textos-visuais portugueses dos séculos XVII e XVIII. Lisboa: I.N.C.M, 1983.

LEHMANN, Hans-Thies. Postdramatic theatre. (Trad. Karen Jürs-Munby). New York: Routledge, 2006.

MCGUIRE, Richard. Here. New York: Pantheon Books, 2014.

MERLEAU-PONTY, Maurice. Fenomenologia da percepção. São Paulo: Martins Fontes, 2006.

O'SHEA, José Roberto. Introdução. In: SHAKESPEARE, William. O Primeiro Hamlet: inquarto de 1603. (org. e trad. José Roberto O’Shea). São Paulo: Hedra, 2013.

RICARDO, Francisco (ed.). Literary art in digital performance: case studies in new media art and criticism. New York: Continuum, 2009.

STOPPARD, Tom. Rosencrantz and Guildenstern are dead. New York: Grove Press, 1991.

TAVARES, Otávio G. Ação e artifício. 2015. 439f. Tese (Doutorado em Literatura) Programa de Pós-Graduação em Literatura, Centro de Comunicação e Expressão, UFSC. Florianópolis, 2015. Disponível em: http://www.bu.ufsc.br/teses/PLIT0631-T.pdf. Acesso em: 27 ago. 2017.

THOMASSON, Amie. Fiction and metaphysics. New York: Cambridge University Press, 1999.

WILTON, Azevedo. Atame: a angústia do precário. (versão DVD). São Paulo: Mackenzie, 2006. Versão demostrando o funcionamento do DVD. Disponível em:

https://www.youtube.com/watch?v=YzYF3QYuHiI. Acessado em: 02 abr. 2018 
. Atame: a angústia do precário (versão Youtube). Disponível em:

https://www.youtube.com/watch?v=jJIDn0nv3Ag. Acessado em: 02 abr. 2018.

. Atame: a angústia do precário (poemas transcritos). 2006. Disponível em:

https://elmcip.net/sites/default/files/media/work/attachments/atame_-

_texto_de_acordo_com_o_cd.pdf. Acessado em: 02 abr. 2018. 